\title{
Ringertz Tumor with Malignant Transformation
}

\author{
${ }^{1}$ Sumit Prinja, ${ }^{2}$ Jai L Davessar, ${ }^{3}$ Heera Luthra, ${ }^{4}$ Manpreet Kaur
}

\begin{abstract}
Introduction: An inverted papilloma is a benign tumor that is found in the nasal cavity or paranasal sinuses. Inverted papilloma accounts for approximately 0.5 to $2.0 \%$ of all nasal tumors. While it is considered benign, an inverted papilloma can destroy the surrounding bone. In a small number of cases (5-15\%), an inverted papilloma may be found with a squamous cell carcinoma; one such case is reported.
\end{abstract}

Case report: A 70-year-old male presented with complaints of right-sided nasal blockage, which progressively increased over time and nasal discharge since one and half years with occasional history of epistaxis. On anterior rhinoscopic examination, there was a fleshy polypoidal mass filling the right nasal cavity. Contrast-enhanced computed tomography revealed a soft tissue density mass filling maxillary sinus and posterior choana with mild enhancement. Endoscopic medial maxillectomy was performed with complete removal of mass. Histopathological diagnosis was given as inverted sinonasal papilloma with malignant transformation. The patient was referred to a cancer reference center for treatment and received combined radiotherapy and chemotherapy. Patient was disease free at 6 -month follow-up.

Conclusion: An inverted papilloma is a benign tumor with a propensity for malignant change. For these reasons, inverted papilloma should be treated like malignant tumor of the nasal cavity and paranasal sinuses.

Keywords: Chemotherapy, Inverted papilloma, Medial maxillectomy, Radiotherapy, Squamous cell carcinoma.

How to cite this article: Prinja S, Davessar JL, Luthra $H$, Kaur M. Ringertz Tumor with Malignant Transformation. Clin Rhinol An Int J 2017;10(1):39-41.

Source of support: Nil

Conflict of interest: None

\section{INTRODUCTION}

The mucosal lining of nose and paranasal sinuses is known as Schneiderian membrane, in memory of Victor Conrod Schneider, who described its histology. Papilloma arising from this membrane is very unique in that they are found to be growing inwardly and, hence, the term

\footnotetext{
${ }^{1}$ Assistant Professor, ${ }^{2}$ Professor, ${ }^{3,4}$ Postgraduate Student

${ }^{1-4}$ Department of ENT, Guru Gobind Singh Medical College \& Hospital, Faridkot, Punjab, India

Corresponding Author: Sumit Prinja, Assistant Professor Department of ENT, Guru Gobind Singh Medical College \& Hospital, Faridkot, Punjab, India, Phone: +911632220437, e-mail: Prinja2001@yahoo.com
}

inverted papilloma. Ringertz, in 1938, was the first to describe the microscopic appearance and the tendency of the tumor to invert into the connective tissue stroma. ${ }^{1}$ An inverted papilloma is a benign tumor that is rarely found in the nasal cavity or paranasal sinuses. Inverted papillomas account for approximately 0.5 to $2.0 \%$ of all nasal tumors and are most frequently seen in patients 40 to 60 years of age. There is a significant predilection for males (M:F = 4:1). While it is considered benign, an inverted papilloma can destroy the surrounding bone. It grows deeply into the tissues near the sinuses, including the brain, and can cause death, if left untreated. In a small number of cases (5-15\%), an inverted papilloma may be found with a squamous cell carcinoma. For these reasons, inverted papilloma is treated like malignant tumor of the nasal cavity and paranasal sinuses. Inverted papilloma can be classified according to its site of occurrence, i.e., lateral wall and septal papilloma. They show differences in their behavior patterns. The septal papilloma remains confined to the nasal septum and may very rarely involve the roof and floor of the nasal cavity. Carcinomatous transformation is rare in septal papilloma. Papilloma of lateral wall is known to involve multiple sites, i.e., floor, roof of nasal cavity, paranasal sinuses, and nasolacrimal duct. ${ }^{2}$ Carcinomatous transformation is common in this variety. ${ }^{3}$

\section{CASE REPORT}

A 70-year-old male resident of Faridkot came to the outpatient Department of ENT, with complaints of rightsided nasal blockage, which had progressively increased over time and nasal discharge since one and half years with occasional history of epistaxis.

General physical examination was unremarkable. On anterior rhinoscopic examination, there was a fleshy polypoidal mass filling the right nasal cavity (Fig. 1). It was insensitive on touch, soft in consistency, and bled on probing. Postnasal examination revealed the mass extending into the nasopharynx. Rest of the ear, nose, and throat examination was within normal limits. Contrast-enhanced computed tomography (CT) revealed a soft tissue density mass filling maxillary sinus and posterior choana with mild enhancement (Fig. 2).

Routine investigations were within normal limits. Endoscopic medial maxillectomy was performed with complete removal of mass. Hemostasis was achieved and 


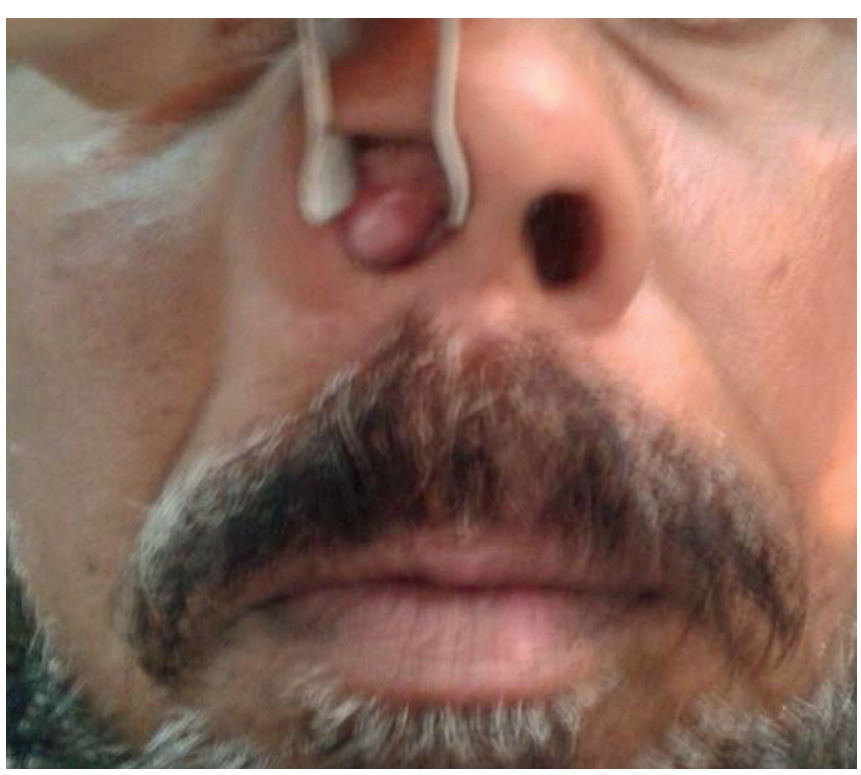

Fig. 1: Nasal mass on anterior rhinoscopy

nasal packing done. Specimen was sent for histopathological diagnosis. Histopathologically, inversion of the thickened and multilayered nonkeratinizing squamous epithelium replacing normal respiratory mucosa in the underlying edematous stroma was seen. Mitotic activity, dyskeratosis, and several degrees of epithelial dysplasia were also found.

The patient was referred to a cancer reference center for treatment and received combined radiotherapy and chemotherapy. Patient was disease-free at 6-month follow-up.

\section{DISCUSSION}

Inverted papillomas account for approximately 0.5 to $2.0 \%$ of all nasal tumors, and are most frequently seen in patients 40 to 60 years of age. ${ }^{3}$ There is a significant predilection for males (M:F = 4:1). While it is considered benign, an inverting papilloma can destroy the surrounding bone. It grows deeply into the tissues near the sinuses, including the brain, and can cause death, if left untreated. Although its etiology remains unknown, it has been associated with human papillomavirus (HPV). Majority of inverted papillomas are located in the nasal cavity itself and present with nasal obstruction, discharge, and, at times, epistaxis. On examination, there is a fleshy polypoidal mass. The CT features are largely nonspecific, demonstrating a soft tissue density mass with some enhancement. The location of the mass is one of the few clues toward the correct diagnosis. Calcification is sometimes observed, which is helpful, as is focal hyperostosis, which tends to occur at the site of tumor origin. ${ }^{4}$ This is useful not only in suggesting the diagnosis, but also to aid surgical planning, as the location of

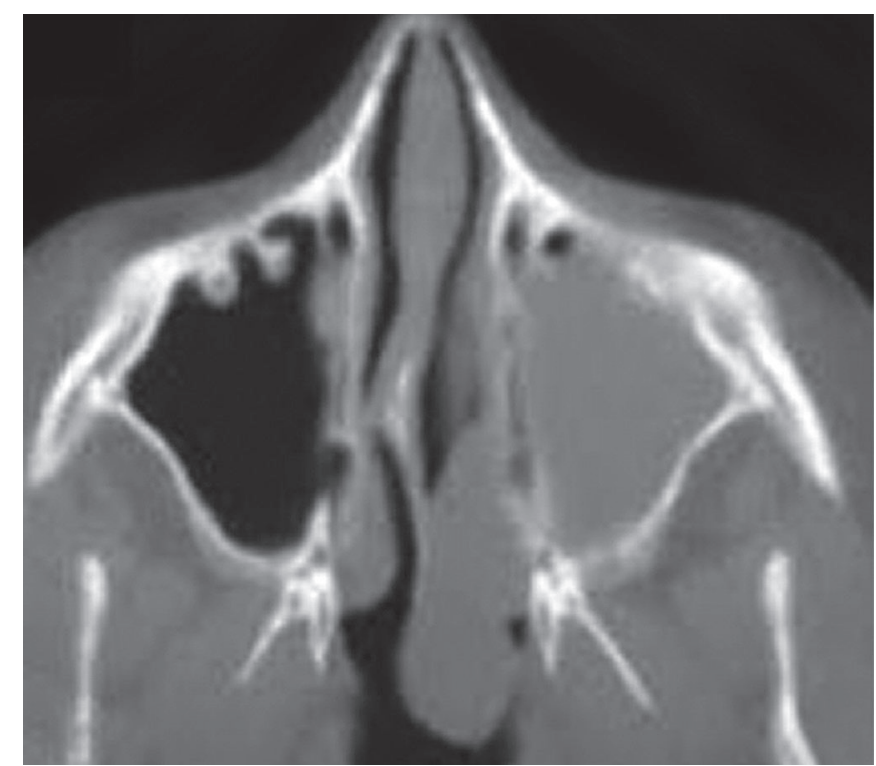

Fig. 2: Axial cut of CT scan of soft tissue density mass filling maxillary sinus and posterior choana

tumor origin determines the extent of surgery required. As the mass enlarges, bony resorption and destruction may be present, with pattern similar to that seen in patients with squamous cell carcinoma. Synder and Perzin ${ }^{5}$ noted a marked atypia and a significant increase in the mucous droplets within the epithelium of recurrent tumors. Investigations like fluorescence in situ hybridization and polymerase chain reaction have been used to determine its link with the HPV types 6 and $11 .{ }^{6}$ Due to their unlimited growth potential, inverted papillomas have historically been resected with the lateral nasal wall (medial maxillectomy) via an external incision. Increasingly, advances in endoscopic techniques have been used to limit the size of resection, and localizing the site of tumor origin is necessary. This is often only possible at the time of surgery, but can be suggested by the presence of focal hyperostosis. Recurrence rates are nonetheless high $(15-78 \%)^{7}$ and are usually attributed to incomplete local resection. Other than malignant transformation and recurrence, morbidity stems from local growth, which can be extensive, extending to adjacent spaces including the orbit and intracranial compartment.

\section{CONCLUSION}

An inverted papilloma is a benign tumor with a propensity for malignant change. For these reasons, inverted papilloma should be treated like malignant tumor of the nasal cavity and paranasal sinuses.

\section{REFERENCES}

1. Ringertz N. The pathology of the malignant tumours which arise in the nasal and the paranasal cavities and the maxilla. Acta Otolaryngol 1938;27:31-42. 
2. Momose $\mathrm{KJ}$, Weber AL, Goodman M, MacMillan AS Jr, Roberson GH. Radiological aspects of inverted papilloma. Radiology 1980 Jan;134(1):73-79.

3. Barnes, L. Pathology and genetics of head and neck tumours. In: Leon Barnes, John W. Eveson, Peter Reichart, David Sidransky, editors.World Health Organization Classification of tumors. Lyon, France: IARC Press, 2005. p.371.

4. Lee DK, Chung SK, Dhong HJ, Kim HY, Kim HJ, Bok KH. Focal hyperostosis on $\mathrm{CT}$ of sinonasal inverted papilloma as a predictor of tumor origin. AJNR Am J Neuroradiol 2007 Apr;28(4):618-621.
5. Synder RN, Perzin KH. Papillomatosis of the nasal cavity and the paranasal sinuses. A clinicopathologic study. Cancer 1972 Sep;30(3):668-690.

6. Buchwald C, Franzmann MB, Jacobson GK, Lindeberg H. The human papilloma virus (HPV) in sino-nasal papillomas: a study of 78 cases by using in-situ hybridization and polymerase chain reaction. Laryngoscope 1995 Jan;105(1): 66-71.

7. Lawson $\mathrm{W}, \mathrm{Ho} \mathrm{BT}$, Shaari CM, Biller HF. Inverted papilloma: a report of 112 cases. Laryngoscope 1995 Mar;105(3 Pt 1): 282-288. 